\section{Graduate Student Award Finalists to Compete at the 1996 MRS Fall Meeting/CEM-96}

Thirty finalists will compete for the MRS Graduate Student Awards to be presented during the awards ceremony on Wednesday, December 4, at 6:00 p.m., in the Boston Marriott Hotel, Salon E. The Graduate Student Award Special Talk Session, in which each finalist gives a 10-minute presentation, will be held on Monday, December 2, at 12:00 noon.

The finalists, all authors or co-authors of

\section{Graduate Student Award Finalists-}

Jochen Betz, CNRS, "Giant Magnetostrictive, Spring Magnet Type Multilayers and TorsionBased Microactuators" (Symposium I)

Wengang (Wayne) Bi, University of California, "A Study of Mixed Group-V Nitrides Grown by Gas-Source Molecular Beam Epitaxy Using an N Radical Beam Source" (Symposium N)

Kenneth Bryden, Massachusetts Institute of Technology, "Nanostructured Palladium Alloy Membrane Materials" (Symposium V)

Darren T. Castro, Massachusetts Institute of Technology, "Synthesis and Sintering of Nanocrystalline Nitride-Based Ceramic Materials" (Symposium V)

Konstantinos Chondroudis, Michigan State University, "Complex Actinide and Rare Earth Polyselenophosphates" and "Synthesis of $\mathrm{Rb}_{4} \mathrm{Sn}_{5}\left(\mathrm{P}_{2} \mathrm{Se}_{6}\right)_{3} \mathrm{Se}_{2}$ : A New Layered MixedValent Metallic Chalcogenide"(Symposium R)

Vi-En Choong, University of Rochester, "Effects of Metals on Luminescence of Organic Materials" (Symposium D)

Elizabeth Dickey, Northwestern University,

"A Combined-Techniques Approach to

Studying Heterophase Interfaces Using HREM, Z-Contrast Imaging and EELS" (Symposium G)

Robert G. Duan, University of Minnesota, "Electrically Conducting Dendrimer Films" (Symposium D)

Jonah Erlebacher, Harvard University, "Morphological Equilibration of Rippled and Dimpled Crystal Surfaces" and "Ion SputteringInduced Rippling of Silicon Surfaces"

(Symposium Ca)

Jonathan E. Guyer, Northwestern University, "The Compositional Stability of Alloy Thin Films" (Symposium Cb)

Jonathon J. Host, Northwestern University, "Magnetic Properties of Graphite Encapsulated Ferromagnetic Nanocrystals" and "Controlled Investigation of Possible Graphite Encapsulated Nanocrystal Formation Mechanisms" (Symposium V)

Noo Li Jeon, University of Illinois-Urbana, "Fabrication of Stacked Capacitors Using a Mask-Less Patterning Process" (Symposium K)

Vicki Keast, Lehigh University, "Investigation of the Bonding Changes Associated with Grain Boundary Embrittlement" (Symposium W) papers to be presented at the $1996 \mathrm{MRS}$ Fall Meeting/ICEM-96, were selected on the basis of the quality and thoroughness of their research, the originality and independence of their contributions, and their promise for future achievement in materials research.

Following is the list of finalists, their places of study, titles of papers, and the symposium or symposia in which the finalists are participating.

\section{MRS Fall Meeting/CEM-96}

Steven D. Leith, University of Washington, "Fabrication and Characterization of NiFe Thin Film Composition Modulated Alloys" and "Modeling Damage to Limestone Exposed to Atmospheric Pollutants" (Symposia P and DD)

Michael M. Lipp, University of California-Santa Barbara, "Collapse Mechanics of Lipid/Protein Monolayers: Relevance to the Functioning of Lung Surfactant" and "Comparison of the Effect of Lung Surfactant Protein SP-B on the Phase Behavior of Binary Mixtures of the Protein with

NEW FEATURES!

2 Beam Dynamical Dislocation \& Stacking Fault Simulation

Full Dynamic CBED Simulation

Full SAD Simulations with Spots,

$\mathrm{K}$-lines and Streaking

Lattice Calculation from Patterns Compare Diffractomer Spectra Rapid Search of EDD, PDF, and NBS/NIST Crystal Databases (purchased separately) and so much more!

VIRTUAL LABORATORIES tel: $1-505-828-1640$ fax: $1-505-822-9759$

http://www.Rto6.com/ virtlabs/

Circle No. 41 on Reader Service Card.

\section{For ISO $900 D_{\text {certification }}$}

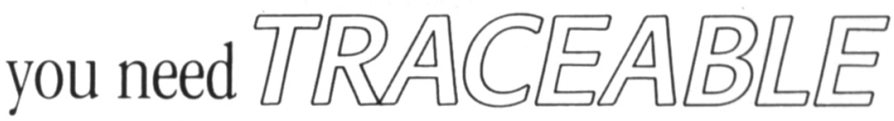
CAIIBRAIIION standards for your METROLOGY. And here's the place to get them

Now, get traceable calibration standards and references for Surface Profiling, Film Thickness, Surface Contamination, Surface Characterization, Electrical, and Critical Dimension metrology, and more. Get the free catalog: VLSI Standards, 3087 N. $1^{\text {st }}$ St., San Jose, CA . 95134. Phone: (408) 428-1800 Fax: (408) 428-9555.

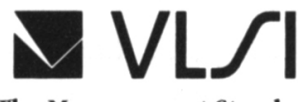

\section{Standards}

Incorporated

The Measurement Standards for the Industry

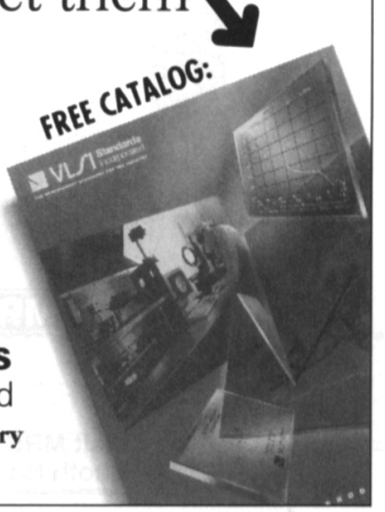

Circle No. 42 on Reader Service Card. 
Anionic Lipids Found in Lung Surfactant" (Symposia EE and FF)

Despina Louca, University of Pennsylvania, "Structure of $\mathrm{La}_{1-x} \mathrm{Sr}_{x} \mathrm{MnO}_{3}$ Studied by Pulsed Neutron Diffraction: Evidence of Lattice Polarons" (Symposium CC)

Marlon Menezes, University of Illinois-Urbana, "Technique to Measure Thermodynamic Adhesion of Copper-Polyimide Interface" and "Novel Technique to Improve Adhesion Between Metal-Polymer Interfaces" (Symposium J)

H. C. Ong, Northwestern University, "The Effect of Laser Intensity on the Properties of Carbon Plasma and Deposited Films" and "Deposition of Nanophase Aluminum Nitride Thin Films by Pulsed Laser Deposition" (Symposia Cb and $\mathrm{N}$ )

Kevin F. Peters, Northwestern University, "Novel Experimentation for In Situ UHV X-ray Diffraction Studies of Phase Transformations in Nanometric Islands of $\mathrm{Pb}$ and $\mathrm{SiO}_{2} / \mathrm{Si}^{\prime \prime}$ and "Small-Particle Melting Phenomena" (Symposia CC and FF)

G. Ramanath, University of Illinois-Urbana,
"Stability of Poly-TiN/Ti/Poly-TiN and PolyTiN/Ti/TiN(100) Structures During Thermal Annealing" and "Surface and Interfacial Reactions in TiN $/ \mathrm{Ti} / \mathrm{SiO}_{2} / \mathrm{Si}(100)$ Structures During $\mathrm{WF}_{6}$ Exposure" (Symposium $\mathrm{Cb}$ )

Anant A. Setlur, Northwestern University, "Synthesis and Properties of Filled Nanotubes" (Symposium D)

Sean M. Seutter, University of Minnesota, "Microscopic Mechanisms of Surface Segregation: Sn-Doped GaAs(100)" (Symposium Cb)

Christine A. Smith, University of CaliforniaDavis, "The Role of Traps in Quantum Confined Zinc Selenide Nanocrystals" (Symposium Q)

Shanthi Subramanian, Cornell University, "Influence of Local Chemistry and Bonding on the Properties of Grain Boundaries in Intermetallic Compounds" and "Chemistry, Bonding and Mechanical Properties of Grain Boundaries in $\mathrm{Ni}_{3} \mathrm{Si}^{\prime \prime}$ (Symposia $\mathrm{W}$ and $\mathrm{Z}$ )

Maggie E. Taylor, California Institute of Technology, "Growth of Epitaxial Si on Dihydride-Terminated Si(001) by Pulsed Laser Deposition" (Symposium Cb)
Alexei Tkachenko, Bar-llan University, "Fluctuations, Lindemann Criterion and Solid-Liquid Transition in Thin Layers" (Symposium EE)

Zoran Trajanovic, University of Maryland ${ }^{\prime} \mathrm{YBa}_{2} \mathrm{Cu}_{3} \mathrm{O}_{7} / \mathrm{Pb}\left(\mathrm{Zr}_{0.5} \mathrm{Ti}_{0.5}\right) \mathrm{O}_{3} /$ Au Ferroelectric Field Effect Transistors" (Symposium GG)

Nicolas Vandewalle, University of Liège, "Multi Grain Growth, Microstructure and Boundary Features in Composite Systems with Competition Growth: Experiments and Simulations" and "Phase Transitions, Patterns, and Statistical Mechanics of Front Propagation in a Dynamic Random Impurity Model for Strip, Unusual Trees and Other Chain Geometries" (Symposia F and EE)

Tracey Wolfsdorf, Northwestern University, "The Morphology of High-Volume Fraction Solid-Liquid Mixtures: An Application of Microstructural Tomography" (Symposium F)

Pei Zeng, University of Connecticut, "Nanoparticle Sintering Simulations" (Symposium F)

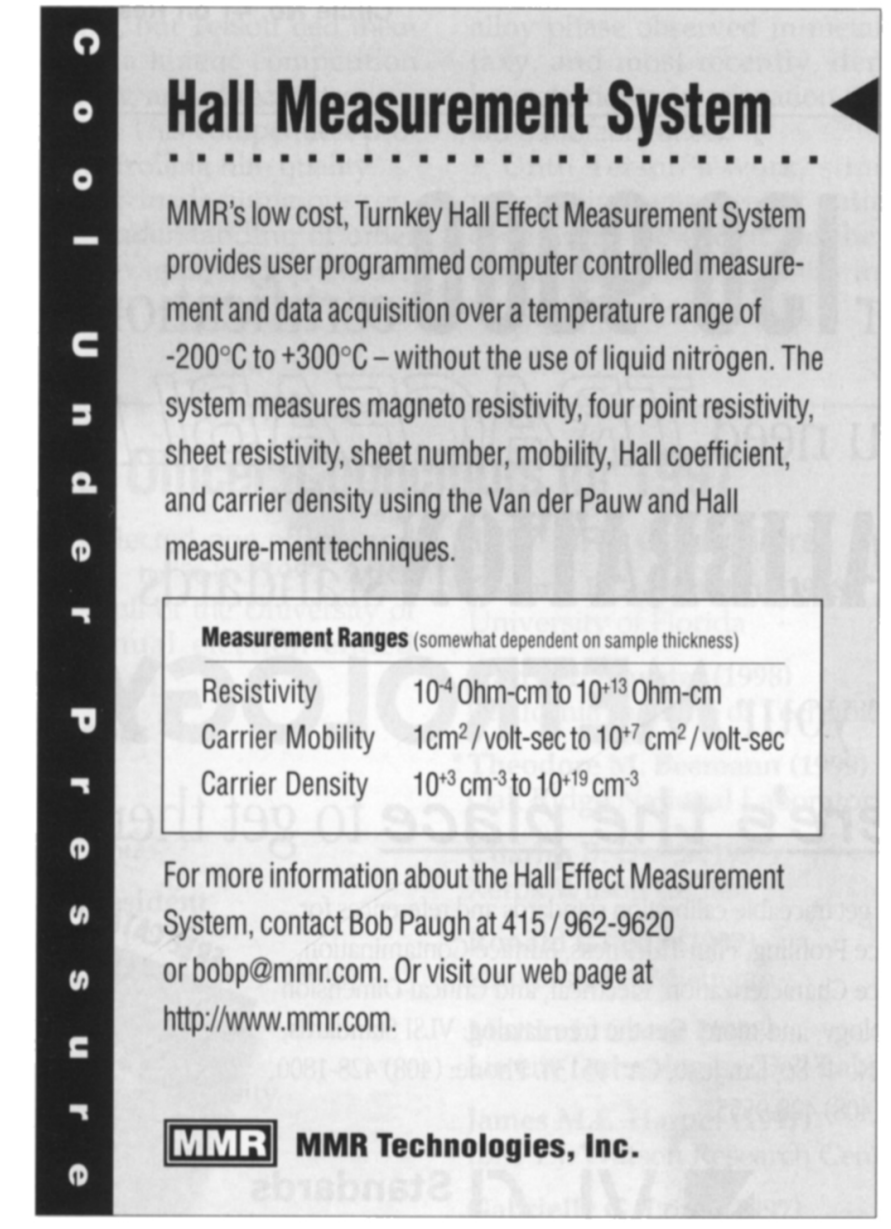

Visit MRS Exhibit Booth No. U321

\section{Advanced Chemicals \& Materials Processing $\infty$}

- Electronic Grade Red Phosphorus

- InP polycrystalline charge, single crystals, wafers

- GaN powder \& submillimeter size single crystals

- Bulk growth of III-V compound crystals with custom doping \& orientation

- R\&D Consulting Services for the Electronics Materials Industry

- Outsource and/or subcontract R\&D and manufacturing services

- Materials Purification

- Custom Single Crystals

- Custom Equipment Design

VIs/t Our Booth at the Fall MRS Exhlbitton In Boston, Dec 3-5, 1996

Parke Mathematical Laboratories 450 Chelmsford Street Lowell, MA 01851

(508) 934-0854 FAX (508) 934-0731 E-mail: pml oparkemath.com Web Site: http://www.parkemath.com

Circle No. 28 on Reader Service Card.

Visit MRS Exhibit Booth No. W24 